Research Article

\title{
High Maternal Neonatal Mortality and Morbidity in Pregnancy with Eisenmenger Syndrome
}

\author{
Erry Gumilar Dachlan, ${ }^{1}$ Amirah, ${ }^{2}$ Nareswari Cininta, ${ }^{1}$ Rizky Pranadyan, ${ }^{1}$ \\ Alisia Yuana Putri, ${ }^{3}$ Yudi Her Oktaviono, ${ }^{3}$ and Muhammad Ilham Aldika Akbar $\mathbb{D}^{1,4}$ \\ ${ }^{1}$ Department Obstetrics \& Gynecology Faculty of Medicine Universitas Airlangga, Dr. Soetomo General Academic Hospital, \\ Surabaya, Indonesia \\ ${ }^{2}$ Department Obstetrics \& Gynecology Fakfak General Hospital, West Papua, Indonesia \\ ${ }^{3}$ Department Cardiology Faculty of Medicine Universitas Airlangga, Dr. Soetomo General Academic Hospital, Surabaya, Indonesia \\ ${ }^{4}$ Department Obstetrics \& Gynecology Faculty of Medicine Universitas Airlangga, Universitas Airlangga Hospital, \\ Surabaya, Indonesia
}

Correspondence should be addressed to Muhammad Ilham Aldika Akbar; muhammad-i-a-a@fk.unair.ac.id

Received 25 April 2021; Revised 20 August 2021; Accepted 20 September 2021; Published 27 September 2021

Academic Editor: Kaushik Maiti

Copyright (C) 2021 Erry Gumilar Dachlan et al. This is an open access article distributed under the Creative Commons Attribution License, which permits unrestricted use, distribution, and reproduction in any medium, provided the original work is properly cited.

\begin{abstract}
Objectives. This study is aimed at evaluating the maternal and perinatal characteristics and pregnancy outcomes of ES. Material and Methods. This is a retrospective cohort study of pregnancy with Eisenmenger syndrome (ES) in Dr. Soetomo Hospital from January 2018 to December 2019. Total sampling size was obtained. We collected all baseline maternal-perinatal characteristic data, cardiac status, and pregnancy outcomes as primary outcomes. The maternal death cases were also evaluated, and we compared characteristics based on defect size $(<$ or $>3 \mathrm{~cm})$. Results. During study periods, we collected 18 cases with ES from a total of 152 pregnancies with heart disease. The underlying heart disease type includes atrial septal defect (ASD), ventricle septal defect (VSD), and patent ductus arteriosus (PDA). All cases suffered pulmonary hypertension (PH), 3 cases moderate, and 15 cases as severe. $94 \%$ of cases fall into heart failure (DC FC NYHA III-IV) during treatment. The majority of cases are delivered by cesarean section (88.9\%). Pregnancy complications found include preterm birth (78\%), low birthweight (94\%), intrauterine growth restriction (55\%), oligohydramnios (16\%), severe preeclampsia (33\%), and placenta previa (5.5\%). Large defect group has an older maternal ages (30.18 \pm 4.60 vs. $24.15 \pm 2.75 ; p=0.002)$, higher clinical sign (100 vs. $40 \%, p=0.003)$, and higher preterm delivery rate $(100 \%$ vs. $69 \%, p=0.047)$ compared to small defect groups. The $\mathrm{R}$ to $\mathrm{L}$ or bidirectional shunt is significantly higher at the large defect group (13 vs. 5 cases, $p=0.006,95 \%$ confidence interval: -1.156 to -0.228). There were seven maternal death cases caused by shock cardiogenic. Conclusions. Pregnancy with ES is still associated with very high maternal neonatal mortality and morbidity. The larger defect size is correlated with clinical performances and pregnancy outcomes. Effective preconception counseling is the best strategy to reduce the risk of maternal and neonatal death in ES women.
\end{abstract}

\section{Introduction}

Maternal heart disease is the second common cause of maternal death after preeclampsia. One of the most frequent heart disease types in pregnancy is congenital heart disease in which $5 \%$ of the patients have pulmonal hypertension [1]. Eisenmenger syndrome (ES) represents the severe end of the spectrum for disease in pulmonary arterial hypertension associated with congenital heart defect (PAH-CHD). Eisenmenger syndrome due to $\mathrm{PAH}-\mathrm{CHD}$ is classified into group one. It is defined by systemic-to-pulmonary shunting of blood through any large congenital cardiac defects at any location permitting increased pulmonary blood flow that progress into severe elevation of pulmonary vascular resistance (PVR) resulting in reversal (pulmonary-to-systemic) or bidirectional shunting [2]. The defect is considered inoperable. 
Hemodynamically, ES is defined as the elevation of PVR to 12 Wood unit or to a pulmonary-to-systemic resistance ratio equal to or greater than 1.0. The size of shunt and exact diameter of the defect do matter. The threshold is $2-3 \mathrm{~cm}$ at atrial level, $1-1.5 \mathrm{~cm}$ at ventricular level, and $0.5-0.7 \mathrm{~cm}$ at arterial level. Fifty percent of patients with a large defect in the ventricular level developed ES, and 13\% percent of patients with large defect at the atrial level develop ES [3].

The prevalence of ES is not well-known. Recent data showed that $4.2 \%$ of adult CHD patients develop PAH$\mathrm{CHD}$, and one percent had ES. The incidence of ES is even lower in pregnancy, approximately around 3\% in pregnant women with congenital heart disease [4]. Patients with ES who become pregnant have a very high risk of adverse pregnancy outcomes. Maternal mortality is reported $30-50 \%$, and most of it is caused by rapidly progressive cardiopulmonary decompensation, thrombotic complications, and sudden death due to malignant arrhythmia [5]. Because of the high risk of maternal mortality, pregnancy is contraindicated in women with ES [6]. Adverse pregnancy outcomes found in ES are abortion, intrauterine growth restriction/IUGR (30\%), and preterm birth (50-60\%) which are all related to maternal chronic hypoxia [7]. Eisenmenger syndrome is often diagnosed and managed late, especially in developing countries. This is related to the low awareness and knowledge in the community and social and economic factors that delay access to public health services [8]. This study is aimed at evaluating the maternal, perinatal, and pregnancy outcomes of ES.

\section{Materials and Methods}

2.1. Study Population and Outcomes. This is a retrospective cohort study of pregnancy with ES cases at Dr. Soetomo General Academic Hospital, Surabaya, East Java, Indonesia, from January 2018 to December 2019. Dr. Soetomo General Academic Hospital is the top referral tertiary center hospital in East Java, Indonesia. The study population was pregnant women with heart disease who were managed in our hospital during study periods. The inclusion criteria were all pregnant or postpartum women with ES. There are no exclusion criteria in this study. We used a total sampling size. The ethical clearance of this study was approved by the Ethical Committee Board of Dr. Soetomo Hospital Written informed consent has been acquired from all the participants. The primary outcomes of this study are maternal, perinatal, and pregnancy outcomes in Eisenmenger syndrome. Pregnancy outcomes evaluated consist of maternal mortality, obstetrics complications (abnormal cardiotocography test, oligohydramnios, severe preeclampsia, and IUGR), heart failure, preterm delivery rate, mode of delivery, baby birthweight, and Apgar score. We also assessed the maternal characteristics and the maternal cardiac status. Maternal characteristics include maternal ages, gestational age at diagnosis and delivery, gravidity, antenatal care history, heart disease type, and heart failure. Cardiac status includes heart disease type, murmur sign, clubbing finger, arterial oxygen saturation $\left(\mathrm{SaO}_{2}\right)$, defect size, and pulmonary arterial systolic pressure $(\mathrm{mmHg})$. The defect size and pulmonary arterial systolic pressure were determined using echocardiography examination, while the other cardiac parameters were found from the physical examination. We also evaluated the correlation between maternal and perinatal characteristics and pregnancy outcomes with the cardiac defect size. We divided the samples into two groups based on the defect size: small $(<3 \mathrm{~cm})$ and large $(>3 \mathrm{~cm})$ defect groups. The clinical characteristics of all maternal death cases were also described.

We defined abnormal cardiotocography as a finding of category two or three based on National Institute of Child Health and Human Development criteria [9]. Oligohydramnios was diagnosed as an amniotic fluid index $<5 \mathrm{~cm}$, from fetal ultrasound [10]. We defined preeclampsia as gestational hypertension accompanied by $>1$ of the following new-onset conditions after 20-week gestation: proteinuria, maternal organ dysfunction, or uteroplacental dysfunction [11]. IUGR was defined based on ultrasound finding of estimated fetal weight $<10$ percentile [12]. Heart failure was categorized based on the New York Heart Association (NYHA) functional class [13]. Preterm was defined as delivery before 37-week gestation [14-16]. Apgar score was used to evaluate general health and sign of hemodynamic compromise of the newborn. Score $<7$ was defined as low Apgar scores [17].

2.2. Echocardiography Procedure. Transthoracic echocardiography (TTE) was performed by adult cardiology fellows. All the procedures were supervised, and all the results are discussed by the senior cardiologist from echocardiology and adult congenital heart disease division to minimize interoperator variation bias. The heart scanning machine was Echo Vivid E9 GE and EchoPAC Dimension system (General Electric Healthcare, US) with the procedure as follows:

(1) All TTE parameters were examined based on American Society of Cardiography (ASE) recommendation

(2) Two-dimensional modes were scanned from all views, including parasternal long axis (PLAX), parasternal short axis (PSAX), apical 4-chamber, apical 2-chamber, subcostal, and suprasternal

(3) Pulse-wave (PW) Doppler and colour-wave (CW) Doppler mode were scanned from all views to detect any cardiac lesion and shunts

(4) Left ventricle (LV) systolic function was estimated using Teichholz methods from M-mode in PLAX and also using modified Simpson's methods in an apical 4-chamber and 2-chamber view

(5) Left ventricle (LV) diastolic function was measured using PW Doppler and tissue Doppler imaging (TDI) in a 4-chamber view

(6) Probability of pulmonal hypertension related to congenital heart defect was estimated by the addition of tricuspid regurgitation maximal pressure gradient (TR max. PG) and estimated right atrial pressure (est. RAP). Estimated pulmonal artery pressure 
(Est. PASP) is also assessed from peak velocity of tricuspid regurgitation (TR V max) and other PH signs from the ventricle, pulmonary artery, inferior vena cava, and right atrium

2.3. Statistical Analysis. The data of maternal and perinatal characteristics were evaluated using descriptive analysis. The categorical variables were compared between groups using the chi-square test or Fisher exact test based on its distribution. The numerical variables were compared using an independent $t$-test. All statistical tests were performed using IBM Statistics SPSS 25.

\section{Results}

3.1. Maternal and Perinatal Characteristic. During study periods, we collected a total of 152 pregnant and postpartum women with heart disease. Among them, there are 18 cases (11.8\%) with ES that consisted of fifteen pregnancies (83\%) and three postpartum cases (17\%). Most cases (90.5\%) were identified as ES on admission to the hospital. The maternal age average was 27.17 years old, and most are in the interval of 20-29 years old (83\%). The majority of cases were primigravida $(61 \%)$. Fifteen $(83 \%)$ cases were referred from lowerlevel hospital/public health services. Only $17 \%$ cases had a regular antenatal care in our hospital and were managed by a multidisciplinary team until delivery (Table 1). Most patients were first diagnosed as having ES in the gestational ages of 28-36 weeks (61\%). The heart diseases found in the study were atrial septal defect (ASD), ventricle septal defect (VSD), and patent ductus arteriosus (PDA) (Table 1).

Pregnancy complications found include preterm birth (78\%), low birthweight (94\%), intrauterine growth restriction (55\%), oligohydramnios (16\%), severe preeclampsia (33\%), and placenta previa (5.5\%). The majority of cases are delivered by cesarean section, and newborns have a low birthweight related to preterm birth. Most cases are straightly sterilized during or after delivery (72\%) (Table 1).

All cases suffered pulmonary hypertension ( $\mathrm{PH})$, which was divided into the moderate (3 cases) and severe type (15 cases). Moderate $\mathrm{PH}$ is defined by the pulmonary artery systolic pressure (PASP) 60-80, and the PASP in severe $\mathrm{PH}$ is $>80$. Echocardiography results show a common defect size of 1-2 cm in PDA (1 case) and VSD cases (4 cases). Defect 2$3 \mathrm{~cm}$ ( 7 case) and large defect $>3 \mathrm{~cm}$ (5 case) are only found in ASD cases. The shunting pattern in the heart was commonly right to left (10 cases), followed by bidirectional ( 5 cases) and left to right (3 cases) flow (Table 2). Unfortunately, most cases fall into heart failure during gestation (94\%), including NYHA classification DC-DC III and DCFC IV. Laboratory parameters, including hemoglobin $(\mathrm{Hb})$, leukocyte, platelet count, hematocrit (Hct), and oxygen saturation, can be seen in Table 2. The mean value of each parameter was as follows: Hb: $13.9 \mathrm{~g} / \mathrm{dL}$, Hct: $41.68 \%$, leukocyte: 10.971 cell $/ \mu \mathrm{L}$, platelet count: $200.667 \mathrm{cell} / \mu \mathrm{L}$, and oxygen saturation: $88 \%$. Most patients have a normal $\mathrm{Hb}$ levels, and only two women have anemia $(\mathrm{Hb}<11 \mathrm{~g} / \mathrm{dL})$. There is only one woman who has an abnormal leukocyte count $(>17.000)$ and four women with thrombocytopenia
TABLE 1: Maternal characteristics and pregnancy outcomes of Eisenmenger syndrome.

\begin{tabular}{|c|c|}
\hline Maternal age (yrs) & $\begin{array}{c}\text { Patient numbers } \\
n(\%)\end{array}$ \\
\hline $20-29$ & $15(83)$ \\
\hline$\geq 30$ & $3(17)$ \\
\hline Maternal age mean (year) & 27.17 \\
\hline \multicolumn{2}{|c|}{ Gestational age on diagnosis (weeks) } \\
\hline$<20$ & $1(5.5)$ \\
\hline $20-27$ & $2(11)$ \\
\hline $28-36$ & $11(61)$ \\
\hline $37-40$ & $1(5.5)$ \\
\hline Postpartum & $3(17)$ \\
\hline \multicolumn{2}{|c|}{ Gestational age at delivery (weeks) } \\
\hline Preterm $(<37)$ & $14(78)$ \\
\hline Term $(\geq 37)$ & $1(5)$ \\
\hline Postpartum & $3(17)$ \\
\hline \multicolumn{2}{|l|}{ Gravidity } \\
\hline Primigravida & $11(61)$ \\
\hline Multigravida & $7(39)$ \\
\hline \multicolumn{2}{|l|}{ Antenatal care } \\
\hline NBC & $15(83)$ \\
\hline $\mathrm{BC}$ & $3(17)$ \\
\hline \multicolumn{2}{|l|}{ Heart disease type } \\
\hline ASD & $13(73)$ \\
\hline VSD & $4(22)$ \\
\hline PDA & $1(5)$ \\
\hline \multicolumn{2}{|l|}{ Heart failure } \\
\hline No heart failure & $1(6)$ \\
\hline DC FC NYHA III & $9(50)$ \\
\hline DC FC NYHA IV & $8(44)$ \\
\hline \multicolumn{2}{|l|}{ Obstetric complications } \\
\hline Abnormal CTG & $2(11)$ \\
\hline Severe preeclampsia & $9(50)$ \\
\hline Placenta Previa & $2(11)$ \\
\hline Oligohydramnios & $2(11)$ \\
\hline IUGR & $9(50)$ \\
\hline \multicolumn{2}{|l|}{ Mode of delivery } \\
\hline Cesarean section & $16(88.9)$ \\
\hline Vaginal delivery & $2(11.1)$ \\
\hline \multicolumn{2}{|l|}{ Contraception methods } \\
\hline Sterilization & $13(72)$ \\
\hline IUD & $1(6)$ \\
\hline No contraception & $3(20)$ \\
\hline \multicolumn{2}{|l|}{ Baby birthweight } \\
\hline$<2500$ gram & $17(94)$ \\
\hline$\geq 2500$ gram & $1(6)$ \\
\hline \multicolumn{2}{|l|}{ Apgar score } \\
\hline $1-3$ & $3(20)$ \\
\hline $4-6$ & $3(20)$ \\
\hline $7-9$ & $9(60)$ \\
\hline
\end{tabular}

NBC: nonbooked case; BC: booked case; ASD: atrial septal defect; VSD: ventricle septal defect; PDA: patent ductus arteriosus; DC FC NYHA: Decompensatio Cordis Functional Class New York Heart Association; CTG: cardiotocography; IUGR: intrauterine growth restriction; IUD: intrauterine device. 
TABLE 2: Cardiac status and laboratory parameters of Eisenmenger syndrome.

\begin{tabular}{lccccccccc}
\hline Case & Heart disease & Murmur & Clubbing finger & $\mathrm{SaO}_{2}(\%)$ & Defect size $(\mathrm{cm})$ & PASP $(\mathrm{mmHg})$ & $\mathrm{Hb}(\mathrm{g} / \mathrm{dL})$ & WBC $(/ \mu \mathrm{L})$ & PLT $(/ \mu \mathrm{L})$ \\
\hline 1 & $\mathrm{ASD}$ & $\mathrm{Y}$ & $\mathrm{N}$ & 97 & 3 & 80.37 & 8.1 & 16,460 & 181,000 \\
2 & $\mathrm{ASD}$ & $\mathrm{Y}$ & $\mathrm{N}$ & 83 & 3 & 91.24 & 15.5 & 11,400 & 284,000 \\
3 & $\mathrm{VSD}$ & $\mathrm{N}$ & $\mathrm{Y}$ & 84 & 1,1 & 45.35 & 18.1 & 8,180 & 125,000 \\
4 & $\mathrm{VSD}$ & $\mathrm{Y}$ & $\mathrm{Y}$ & 88 & 1 & 76 & 18.6 & 9,930 & 100,000 \\
5 & $\mathrm{ASD}$ & $\mathrm{Y}$ & $\mathrm{N}$ & 95 & 2.3 & 69.25 & 11.1 & 7,220 & 200,000 \\
6 & $\mathrm{ASD}$ & $\mathrm{Y}$ & $\mathrm{N}$ & 69 & 3.7 & 133.50 & 19.3 & 9,520 & 142,000 \\
7 & $\mathrm{ASD}$ & $\mathrm{Y}$ & $\mathrm{Y}$ & 84 & 3.9 & 77.28 & 15.1 & 9,640 & 206,000 \\
$8^{*}$ & $\mathrm{ASD}$ & $\mathrm{Y}$ & $\mathrm{Y}$ & 89 & 2.9 & 181.66 & 14.4 & 8,670 & 151,000 \\
$9^{*}$ & $\mathrm{ASD}$ & $\mathrm{Y}$ & $\mathrm{N}$ & 95 & 2.1 & 120.50 & 13.7 & 11,360 & 269,000 \\
$10^{*}$ & $\mathrm{ASD}$ & $\mathrm{Y}$ & $\mathrm{N}$ & 97 & 3.0 & 48.58 & 14.2 & 12,000 & 200,000 \\
$11^{*}$ & $\mathrm{ASD}$ & $\mathrm{Y}$ & $\mathrm{N}$ & 91 & 3.2 & 130.43 & 13.7 & 11,640 & 256,000 \\
$12^{*}$ & $\mathrm{VSD}$ & $\mathrm{Y}$ & $\mathrm{N}$ & 83 & 1.4 & 111 & 13.5 & 9,090 & 274,000 \\
$13^{*}$ & $\mathrm{ASD}$ & $\mathrm{Y}$ & $\mathrm{Y}$ & 78 & 3.1 & 144.89 & 13 & 7,840 & 175,000 \\
14 & $\mathrm{ASD}$ & $\mathrm{N}$ & $\mathrm{N}$ & 94 & 2.4 & 117.42 & 12.7 & 10,350 & 202,000 \\
15 & $\mathrm{VSD}$ & $\mathrm{Y}$ & $\mathrm{N}$ & 90 & 0.7 & 45.34 & 11.8 & 13,650 & 307,000 \\
16 & $\mathrm{PDA}$ & $\mathrm{Y}$ & $\mathrm{N}$ & 95 & 1.4 & 115.67 & 7.9 & 23,530 & 142,000 \\
17 & $\mathrm{ASD}$ & $\mathrm{Y}$ & $\mathrm{N}$ & 81 & 3.4 & 102.79 & 14.3 & 6,480 & 199,000 \\
$18^{*}$ & ASD & $\mathrm{Y}$ & $\mathrm{Y}$ & 89 & 1.7 & 86.43 & 15.8 & 10,520 & 199,000 \\
\hline
\end{tabular}

* indicates maternal death cases. ASD: atrial septal defect; VSD: ventricular septal defect; PDA: patent ductus arteriosus; Y: yes; $\mathrm{N}$ : no; SaO ${ }_{2}$ : arterial oxygen saturation; PASP: pulmonary artery systolic pressure; Hb: hemoglobin; WBC: white blood cell; PLT: platelet count.

$(<150.000)$. Only five cases have a normal oxygen saturation during admission ( $\geq 95 \%$ ), while the others are already in a hypoxia state. Seven cases even show a sign of respiratory failure, with an oxygen saturation $<85 \%$ (Table 2 ).

\subsection{Relationship between Maternal-Perinatal Characteristic} and Cardiac Defect Size. We divided all cases into two groups based on the defect size in the heart, including small defect $(<3 \mathrm{~cm})$ and large defect $(\geq 3 \mathrm{~cm})$ groups. All maternal and perinatal characteristics are compared among these two groups. Maternal ages in the large defect group are significantly older than the small defect group (30.18 \pm 4.60 vs. $24.15 \pm 2.75)$. All cases in the large defect group show a clinical sign of clubbing finger and cyanosis; however, only forty-six percent manifest in the small defect group. Regarding the heart disease type, the large defect group consisted of ASD (100\%), while the small defect has an ASD, VSD, and PDA. All cases in the large defect group end in preterm delivery, compared to sixty-nine percent in the small defect group. All other parameters show no significant difference statistically (Table 3 ).

3.3. Relationship between Defect Size, Shunt Type, and Pulmonary Hypertension. This study evaluated the relationship between pulmonary hypertension, $\mathrm{R}$ to $\mathrm{L}$ or bidirectional shunt, and defect size. The small defect group $(\leq 3 \mathrm{~cm})$ showed a significantly higher proportion of $\mathrm{PH}$ compared to large defect ( 13 vs. 5 cases, $p=0.037,95 \%$ confidence interval: 1.040 to $-0.0 .37)$, but no correlation was found between both parameters $(p=0.063)$. The $\mathrm{R}$ to $\mathrm{L}$ or bidirectional shunt is significantly higher at the large defect group ( 13 vs. 5 cases, $p=0.006,95 \%$ confidence interval: -1.156 to -0.228 ). Contingency coefficient correlation test resulted in $r=0.527$, indicating a strong correlation between bidirectional or R to L shunt with defect size.

3.4. Maternal Death Case. We found seven maternal death cases in this study (38.8\%), and all happened in ASD cases. The cause of death in these cases is a cardiogenic shock after delivery. All cases were lately referred to our hospital in the third trimester in an already deteriorated condition. All cases are complicated by severe $\mathrm{PH}$, three cases by severe preeclampsia, and 1 case by cardioembolic stroke. All maternal deaths have happened in less than two weeks after delivery; the fastest was 16 hours after delivery. The clinical characteristics of maternal death can be seen in Table 4 .

\section{Discussion}

ES is an acquired elevation of pulmonary vascular resistance and pulmonary artery pressure due to a left-to-right intracardiac shunt. These pathological changes lead to a reversal right-to-left or bidirectional shunt, with subsequent cyanosis and polycythemia. As shown in Table 3, over two years, we found most cases are severe $\mathrm{PH}(89 \%)$, which are dominated by right to left shunt (55.6\%). However, most PHT cases arise from the small defect group (72.2\%). In this study, most ES patients come from rural residents in East Java Province, with low socioeconomic-educational level and poor physical status. They got a chronic tolerance to cardiac heart disease by no symptoms over a long period, which eventually manifests in pregnancy. Due to a lack of general 
TABLE 3: Relationship between maternal perinatal characteristic and cardiac defect size.

\begin{tabular}{|c|c|c|c|c|}
\hline Characteristics & $\begin{array}{c}\text { Lesion diameter of }<3 \mathrm{~cm} \\
n(\%)\end{array}$ & $\begin{array}{c}\text { Lesion diameter of } \geq 3 \mathrm{~cm} \\
n(\%)\end{array}$ & Total $(n=18)$ & $p$ \\
\hline \multicolumn{5}{|l|}{ Maternal age (yrs) } \\
\hline $20-29$ & $12(92)$ & $3(60)$ & $15(83)$ & 0.266 \\
\hline$\geq 30$ & $1(8)$ & $2(40)$ & $3(7)$ & \\
\hline Maternal age (yrs) & $24.15 \pm 2.764$ & $30.18 \pm 4.604$ & & $0.002^{*}$ \\
\hline \multicolumn{5}{|l|}{ GA at labor } \\
\hline Preterm & $9(69)$ & $5(100)$ & $14(72)$ & $0.047^{*}$ \\
\hline Term & $1(8)$ & $0(0)$ & $1(6)$ & \\
\hline Postpartum & $3(23)$ & $0(0)$ & $3(12)$ & \\
\hline \multicolumn{5}{|l|}{ Gravida } \\
\hline Primigravida & $9(69)$ & $2(40)$ & $11(61)$ & 0.281 \\
\hline Multigravida & $4(31)$ & $3(60)$ & $7(39)$ & \\
\hline \multicolumn{5}{|l|}{$\mathrm{ANC}$} \\
\hline NBC & $10(77)$ & $5(100)$ & $15(83)$ & 0.082 \\
\hline $\mathrm{BC}$ & $3(23)$ & $0(0)$ & $3(17)$ & \\
\hline \multicolumn{5}{|c|}{ Clubbing finger \& cyanosis } \\
\hline Negative & $7(54)$ & $0(0)$ & $7(38)$ & $0.003^{*}$ \\
\hline Positive & $6(46)$ & $5(100)$ & $11(62)$ & \\
\hline \multicolumn{5}{|l|}{ Hemoglobin level } \\
\hline$<16 \mathrm{~g} / \mathrm{dL}$ & $11(85)$ & $2(40)$ & $13(72)$ & 0.063 \\
\hline$\geq 16 \mathrm{~g} / \mathrm{dL}$ & $2(15)$ & $3(60)$ & $5(28)$ & \\
\hline \multicolumn{5}{|l|}{ Hematocrit } \\
\hline$<40 \%$ & $6(46)$ & $1(20)$ & $7(38)$ & 0.318 \\
\hline$\geq 40 \%$ & $7(54)$ & $4(80)$ & $11(62)$ & \\
\hline \multicolumn{5}{|l|}{$\mathrm{SaO}_{2}$} \\
\hline$<90 \%$ & $11(85)$ & $4(80)$ & $15(83)$ & 0.827 \\
\hline$\geq 90 \%$ & $2(15)$ & $1(20)$ & $3(17)$ & \\
\hline \multicolumn{5}{|l|}{ Heart disease type } \\
\hline ASD & $8(62)$ & $5(100)$ & $13(72)$ & $0.027^{*}$ \\
\hline VSD & $4(30)$ & $0(0)$ & $4(22)$ & \\
\hline PDA & $1(8)$ & $0(0)$ & $1(6)$ & \\
\hline \multicolumn{5}{|l|}{ Delivery methods } \\
\hline Cesarean section & $11(85)$ & $5(100)$ & $16(89)$ & 0.165 \\
\hline Vaginal delivery & $2(5)$ & $0(0)$ & $2(11)$ & \\
\hline \multicolumn{5}{|l|}{ Baby birthweight } \\
\hline$<2,500 \mathrm{~g}$ & $12(92)$ & $5(100)$ & $17(94)$ & 0.552 \\
\hline$\geq 2,500 \mathrm{~g}$ & $1(8)$ & $0(0)$ & $1(6)$ & \\
\hline \multicolumn{5}{|l|}{ Apgar score } \\
\hline $1-3$ & $2(20)$ & $1(20)$ & $3(20)$ & 0.968 \\
\hline $4-6$ & $1(10)$ & $2(40)$ & $3(20)$ & \\
\hline 7-9 & $7(70)$ & $2(40)$ & $9(60)$ & \\
\hline
\end{tabular}

${ }^{*}$ indicates a significant value $(p<0.05)$. GA: gestational age; ANC: antenatal care; NBC: nonbooked case; BC: booked case.

and medical knowledge, these people lack access to health services, especially cardiologists. The majority refused the advice of cardiac surgery on the patients who can receive cardiac health services. The reason is lack of awareness of the increased risk of morbidity and mortality of pregnancy with cardiac disease and its associated ES complica- tions. There is also a lack of preconceptional counseling nor antenatal care with the obstetrician and cardiologist before pregnancy [18].

The clinical manifestation of ES (clubbing finger or cyanosis) also significantly correlated with the defect's size. The larger the defect size, the higher the possibility of clinical 
TABLE 4: Clinical characteristics of maternal death case.

\begin{tabular}{|c|c|c|c|c|c|c|c|}
\hline No. & $\begin{array}{c}\text { Age } \\
\text { (year) }\end{array}$ & Gravida & Possible cause of death time & $\begin{array}{l}\text { Cardiac } \\
\text { lesion }\end{array}$ & Cardiac complication & Obstetric complication & Delivery method \\
\hline 1 & 24 & Primigravida & $\begin{array}{c}\text { Cardiogenic shock } / 16 \text { hrs } \\
\text { after CS }\end{array}$ & ASD-R to $\mathrm{L}$ & $\begin{array}{l}\text { Severe PHT } \\
\text { DCFC IV }\end{array}$ & IUGR fetus & $\begin{array}{c}\mathrm{CS}+\text { tubectomy } \\
\text { bilateral }\end{array}$ \\
\hline 2 & 35 & Multigravida & $\begin{array}{c}\text { Cardiogenic shock/8 days } \\
\text { after CS }\end{array}$ & ASD-R to $\mathrm{L}$ & $\begin{array}{l}\text { Severe PHT } \\
\text { Lung Oedema }\end{array}$ & $\begin{array}{l}\text { Severe preeclampsia } \\
\text { Oligohydramnios }\end{array}$ & $\begin{array}{l}\text { CS + tubectomy } \\
\text { bilateral }\end{array}$ \\
\hline 3 & 20 & Primigravida & $\begin{array}{c}\text { Cardiogenic shock/7 days } \\
\text { after CS }\end{array}$ & ASD-R to $\mathrm{L}$ & Severe PHT & $\begin{array}{l}\text { Severe preeclampsia } \\
\text { Complete placenta previa }\end{array}$ & $\begin{array}{c}\text { CS + tubectomy } \\
\text { bilateral }\end{array}$ \\
\hline 4 & 35 & Multigravida & $\begin{array}{c}\text { Cardiogenic shock/5 days } \\
\text { after CS }\end{array}$ & ASD-R to $\mathrm{L}$ & $\begin{array}{c}\text { Severe PHT } \\
\text { Cardioembolic stroke }\end{array}$ & - & $\begin{array}{l}\mathrm{CS}+\text { tubectomy } \\
\text { bilateral }\end{array}$ \\
\hline 5 & 24 & Primigravida & $\begin{array}{c}\text { Cardiogenic shock/17 hours } \\
\text { after CS }\end{array}$ & ASD-R to L & $\begin{array}{l}\text { Severe PHT } \\
\text { DCFC IV }\end{array}$ & Severe preeclampsia & $\begin{array}{l}\mathrm{CS}+\text { tubectomy } \\
\text { bilateral }\end{array}$ \\
\hline 6 & 24 & Multigravida & $\begin{array}{l}\text { Cardiogenic shock } / 4 \text { days } \\
\text { after delivery }\end{array}$ & ASD-R to $\mathrm{L}$ & Severe PHT & $\begin{array}{c}\text { Underweight } \\
\text { (body mass index }=16) \\
\text { IUGR fetus }\end{array}$ & Vaginal delivery \\
\hline 7 & 25 & Primigravida & $\begin{array}{c}\text { Cardiogenic shock } / 10 \text { days } \\
\text { after CS }\end{array}$ & ASD-R to $\mathrm{L}$ & Severe PHT & $\begin{array}{c}\text { Underweight } \\
\text { (body mass index }=17) \\
\text { IUGR fetus }\end{array}$ & $\begin{array}{l}\mathrm{CS}+\text { tubectomy } \\
\text { bilateral }\end{array}$ \\
\hline
\end{tabular}

signs appearing. The defect size also correlates with the disease's risk of progression, which is shown by the reversal flow pattern in the heart shunt ( $\mathrm{R}$ to $\mathrm{L}$ or bidirectional shunt). The reversal or bidirectional shunt is found prominently in our large defect group compared to the small one. In ES, especially large septal defects, lesions are characterized by high pulmonary pressure and a high pulmonary flow state. ES refers to any untreated congenital cardiac defect with intracardiac communication that leads to pulmonary hypertension, reversal of flow, and cyanosis. The previous left-to-right shunt is converted into a right-to-left shunt secondary to elevated pulmonary artery pressures and associated pulmonary vascular disease $[19,20]$.

El Kayam et al. explained, eventually, that due to increased resistance and decreased compliance of the pulmonary vessels, elevated pulmonary pressures cause the right heart myocardium hypertrophy (RVH). ES begins when RVH causes right heart pressures to exceed the left heart pressure, leading to a reversal of blood flow through the shunt. Consequently, deoxygenated blood returning from the body bypasses the lungs through the reversed shunt and directly to the systemic circulation, leading to cyanosis and resultant organ damage [20].

In pregnant women, the congenital heart diseases that cause pulmonary vascular disease and evolve into ES are mainly VSD, followed by ASD and PDA. Pregnant women with ES may present with clubbing fingers, cyanosis, dyspnea, fatigue, dizziness, or even right heart failure. This study shows that cyanosis and clubbing fingers and cardiac septal lesion were more prominent in larger defect sizes (> $3 \mathrm{~cm}$ ). Blood gas analysis, complete blood count, and oxygen saturation are important factors in pregnant women with ES. Previous studies showed that oxygen saturation $<65 \%$, $\mathrm{Hct}>60 \%$, and $\mathrm{Hb}>18 \mathrm{~g} / \mathrm{dL}$ are predictors of adverse maternal outcomes in pregnancy [21,22]. The majority of this study's cases have oxygen saturation $<85 \%$, with the lowest saturation which is $66 \%$. The mean hematocrit value in this study is relatively high (42\%) compared to a similar study from India (35.3\%) [23]. Most cases show polycythemia $(\mathrm{Hb}>16 \mathrm{~g} / \mathrm{dL})$, indicating chronic hypoxia (Table 2$)$. Pregnant women with ES should be hospitalized after the 20th week of pregnancy-or earlier if clinical deterioration occurs [20,24-26]. A person with ES is paradoxically subject to the possibility of both uncontrolled bleeding due to damaged capillaries and high pressure and spontaneous clots due to hyperviscosity and blood stasis [27].

ES in pregnancy can cause severe complications, although successful delivery has been reported. Maternal mortality ranges from $30 \%$ to $60 \%$ and may be attributed to heart failure, venous thromboembolic event, hypovolemia, or cardiogenic shock. Six cases have a defect size $>2$ $\mathrm{cm}$, and even three of them have $>3 \mathrm{~cm}$ defect. Most deaths occur either during or within the two weeks after delivery. Study shows that $10 \%$ of women with ES are deceased within 14 days after delivery. Even in ES related to congenital heart disease, this number increases by $28 \%$, and the average survival time is only six days [28]. All maternal death in this study is caused by cardiogenic shock and suffered a severe $\mathrm{PH}$. This study's most maternal death has happened less than two weeks after delivery, related to redistribution of fluid in postpartum periods. This volume overload will exceed the heart capacity with a defect and lead to complications such as heart failure, atrial fibrillation, pulmonary edema, or shock cardiogenic. Katsurahgi et al. study mentioned that from 73 cases of ES, the majority of death was on postpartum periods compared to antepartum ( 23 vs. 3 cases) [29]. Three maternal death cases coincide with severe $\mathrm{PE}$, which complicated the hemodynamic changes in patients with ES. Maternal mortality in heart disease is still high three until four weeks after delivery [30]. The first two-week postpartum is the highest risk of maternal death in pregnancy with heart disease. This finding may suggest the need to prolong women with heart disease in the intensive care unit after delivery. All maternal death cases come in 
an already severe condition related to the late referral. All cases are already complicated by severe $\mathrm{PH}$, heart failure (DC FC NYHA III-IV), and low oxygen saturation. Although a multidisciplinary team has managed patients in the ICU and the pregnancy was immediately terminated, the disease's progression cannot be stopped. All patients died $<10$ days after delivery.

Most patients delivered by cesarean section (88\%). Only two women deliver vaginally; both are in nonviable and periviable gestational age. One case is in pregnancy with severe $\mathrm{PH}$ in the first trimester (12 weeks), which is terminated due to an increased risk of maternal mortality if the pregnancy is continued. The woman is 24 years old and not aware of her congenital heart disease before pregnancy. The other case is the first pregnancy on 27-week gestation and complicated by perimembranous VSD, moderate $\mathrm{PH}$, and ES. Delivery is indicated due to the worsening condition of the mother and born 800-gram babies with a low Apgar score. Unfortunately, this mother passed away 48 hours after delivery. Although there is no evidence of a superior mode of delivery in heart disease, cesarean delivery is preferable in case of severe heart disease with a poor maternal condition such as ES. Vaginal delivery benefits from lower blood loss, risk of thromboembolism, and risk of infection compared to cesarean section. However, vaginal delivery should be performed with a device (forceps extraction or vacuum) to accelerate the second stage in a term gestation [31]. Our hospital's preferred delivery model is decided by the multidisciplinary team, including obstetricians, intensivists, anesthesiologists, cardiologists, and perinatologists. In the most condition of ES, the cesarean is favorable due to the faster procedure, more tight monitoring, and more controllable maternal condition. In cesarean delivery, the mother also does not have to face the uterine contraction, which massively increases cardiac output and heart failure risk [21].

The outcomes of pregnant women with ES in this study are poor. Ninety-four percent (17 cases) of babies were born in preterm gestation with birthweight $<2500$ grams. Ten babies were confirmed to have an IUGR condition after being born from the Ballard-Lutchenzko score [32]. ES in pregnancy is a significant risk factor of IUGR, and the majority deliver in preterm gestation $[2,4,26,29]$. However, the prevalence of IUGR in pregnancy with corrected congenital heart disease (without severe residual defects) is only 8 out of 50 pregnancies (16\%) [33]. Another study shows that neonatal outcomes in the corrected heart are much better compared to the uncorrected, including prematurity $(0$ vs. $40 \%)$, IUGR ( $20 \%$ vs. $40 \%)$, neonatal death (0 vs. $10 \%)$, and baby birthweight (2.17 kg vs. $1.62 \mathrm{~kg})$ [34]. Unfortunately, in this study, all cardiac lesions are uncorrected for the reason that was already explained. The neonatal complication found includes respiratory distress syndrome (9 cases), early-onset sepsis (1 case), and necrotizing enterocolitis (1 case).

\section{Conclusions}

Pregnancy with ES, incredibly complicated by $\mathrm{PH}$, is still associated with very high maternal and fetal morbidity and mortality. Effective preconception counseling is essential to correct heart disease before pregnancy. Termination of pregnancy in the first trimester is advisable in severe heart diseases such as ES and PH. Maternal risks would increase significantly if the pregnancy continued until the third trimester. Suppose the ES patient with PH wishes to carry on the pregnancy. In that case, they should be monitored closely and managed in a tertiary center with collaborative efforts among obstetricians, cardiologists, anesthesiologists, pediatricians, and intensivists. There is no standardized approach to the management of ES in pregnancy; successful perinatal outcomes seem heavily dependent on each patient's individualization of treatment.

\section{Data Availability}

The data is available on request via the institutional board of Dr. Soetomo General Academic Hospital. The authors do not own the data. The data right is held by Dr. Soetomo General Academic Hospital.

\section{Ethical Approval}

The Ethical Committee approved all procedures in this study of Dr. Soetomo General Academic Hospital (Surabaya, Indonesia) following the institutional and national research committee's ethical standards and with the 1964 Helsinki declaration and its later amendments or comparable ethical standards.

\section{Consent}

Informed consent was obtained from all individual participants in this study.

\section{Conflicts of Interest}

The authors declare no conflict of interest in this study.

\section{References}

[1] V. Stangl, J. Schad, G. Gossing, A. Borges, G. Baumann, and K. Stangl, "Maternal heart disease and pregnancy outcome: a single-centre experience," European Journal of Heart Failure, vol. 10, pp. 855-860, 2008.

[2] V. T. M. Borges, C. G. Magalhães, A. M. V. C. Martins, and B. B. Matsubara, "Eisenmenger syndrome in pregnancy," Arquivos Brasileiros de Cardiologia, vol. 90, pp. e39-e40, 2008.

[3] L. Daliento, J. Somerville, P. Presbitero et al., "Eisenmenger syndrome factors relating to deterioration and death," European Heart Journal, vol. 19, pp. 1845-1855, 1998.

[4] S. M. Yuan, "Eisenmenger syndrome in pregnancy," Brazilian Journal of Cardiovascular Surgery, vol. 31, pp. 325-329, 2016.

[5] C. S. Hjortshøj, A. S. Jensen, K. Sørensen et al., "Epidemiological changes in Eisenmenger syndrome in the Nordic region in 1977-2012," Heart, vol. 103, pp. 1353-1358, 2017.

[6] K. K. Stout, C. J. Daniels, J. A. Aboulhosn et al., "2018 AHA/ACC guideline for the management of adults with congenital heart disease: a report of the American College of 
Cardiology/American Heart Association task force on clinical practice guidelines," Circulation, vol. 139, pp. 698-800, 2019.

[7] R. F. Liberman, K. D. Getz, A. E. Lin et al., "Delayed diagnosis of critical congenital heart defects: trends and associated factors," Pediatrics, vol. 134, pp. e373-e381, 2014.

[8] K. V. Wilamarta, Y. Yuniadi, J. Rachmat, D. Fakhri, T. Hakim, and M. Anwar, "Adult congenital cardiac surgery in Indonesia," Cardiology in the Young, vol. 21, pp. 639-645, 2011.

[9] G. A. Macones, G. D. V. Hankins, C. Y. Spong, J. Hauth, and T. Moore, "The 2008 National Institute of Child Health and Human Development workshop report on electronic fetal monitoring: update on definitions, interpretation, and research guidelines," Journal of Obstetric, Gynecologic, and Neonatal Nursing, vol. 37, pp. 510-515, 2008.

[10] M. Lord, S. Marino, and M. Kole, "Amniotic fluid index," Diagnostic Ultrasound, pp. 177-177, 2021, https://www.ncbi .nlm.nih.gov/books/NBK441881/.

[11] M. A. Brown, L. A. Magee, L. C. Kenny et al., "Hypertensive disorders of pregnancy: ISSHP classification, diagnosis, and management recommendations for international practice," Hypertension, vol. 72, pp. 24-43, 2018.

[12] A. Lausman, J. Kingdom, R. Gagnon et al., "Intrauterine growth restriction: screening, diagnosis, and management," Journal of Obstetrics and Gynaecology Canada, vol. 35, pp. 741-748, 2013.

[13] C. Bredy, M. Ministeri, A. Kempny et al., "New York Heart Association (NYHA) classification in adults with congenital heart disease: relation to objective measures of exercise and outcome," European Heart Journal - Quality of Care and Clinical Outcomes, vol. 4, pp. 51-58, 2018.

[14] NICE, "Preterm labour and birth," November 2015, https:// www.nice.org.uk/guidance/ng25/resources/preterm-labourand-birth-pdf-1837333576645.

[15] E. Chandraharan and S. Arulkumaran, "Recent advances in management of preterm labor," Obstetrics and Gynecology, vol. 55, pp. 118-124, 2005.

[16] WHO, "WHO recommendations on interventions to improve preterm birth outcomes," 1st edition, WHO, editor. WHO Library Cataloguing in Publication data; 2015.1-96. Available from: http://www.who.int/reproductivehealth.

[17] L. V. Simon, M. F. Hashmi, and B. N. Bragg, "APGAR score," 2021, https://pubmed.ncbi.nlm.nih.gov/29262097/.

[18] P. R. James, "The importance of pre-pregnancy counselling in cardiac disease," British Journal of Cardiology, vol. 21, pp. 2228, 2014.

[19] G. Gangakhedkar, R. Chhabria, S. Gour, and Y. Palani, "Emergency caesarean section of a patient with Eisenmenger's syndrome: a tight-rope walk," Annals of Cardiac Anaesthesia, vol. 23, pp. 95-97, 2020.

[20] U. Elkayam, S. Goland, P. G. Pieper, and C. K. Silversides, "High-risk cardiac disease in pregnancy: part I," Journal of the American College of Cardiology, vol. 68, pp. 396-410, 2016.

[21] B. J. Koos, "Management of uncorrected, palliated, and repaired cyanotic congenital heart disease in pregnancy," Progress in Pediatric Cardiology, vol. 19, pp. 25-45, 2004.

[22] R. Wald, G. Veldtman, F. Golding, J. Kirsh, B. McCrindle, and L. Benson, "Determinants of outcome in isolated ventricular noncompaction in childhood," American Journal of Cardiology, vol. 94, pp. 1581-1584, 2004.

[23] T. Kaur, P. Pai, and P. Kumar, "Hematocrit as a simple method to predict and manage ovarian hyperstimulation syndrome in assisted reproduction," Journal of Human Reproductive Sciences., vol. 8, pp. 93-97, 2015.

[24] B. J. Hartwig and B. Schultze, "Review of evidence for bosentan therapy for treatment of Eisenmenger syndrome," Journal of the American Association of Nurse Practitioners, vol. 31, pp. 72-77, 2019.

[25] H. Nashat, C. Montanaro, W. Li et al., "Atrial septal defects and pulmonary arterial hypertension," Journal of Thoracic Disease, vol. 10, pp. S2953-S2965, 2018.

[26] H. Basit, T. J. Wallen, and B. N. Sergent, "Eisenmenger syndrome," StatPearls, vol. 7, pp. 11-14, 2021.

[27] H. Wang, W. Zhang, and T. Liu, "Experience of managing pregnant women with Eisenmenger's syndrome: maternal and fetal outcome in 13 cases," The Journal of Obstetrics and Gynaecology Research, vol. 37, pp. 64-70, 2011.

[28] E. Bédard, K. Dimopoulos, and M. A. Gatzoulis, "Has there been any progress made on pregnancy outcomes among women with pulmonary arterial hypertension?," European Heart Journal, vol. 30, pp. 256-265, 2009.

[29] S. Katsurahgi, C. Kamiya, K. Yamanaka et al., "Maternal and fetal outcomes in pregnancy complicated with Eisenmenger syndrome," Taiwanese Journal of Obstetrics \& Gynecology, vol. 58, pp. 183-187, 2019.

[30] G. Fang, Y. K. Tian, and W. Mei, “Anaesthesia Management of Caesarean Section in Two Patients with Eisenmenger's Syndrome," Anesthesiology Research and Practice., vol. 2011, article 972671, 4 pages, 2011.

[31] V. Regitz-Zagrosek, J. W. Roos-Hesselink, J. Bauersachs et al., "2018 ESC guidelines for the management of cardiovascular diseases during pregnancy," European Heart Journal, vol. 39, pp. 3165-3241, 2018.

[32] J. L. Ballard, J. C. Khoury, K. Wedig, L. Wang, B. L. EilersWalsman, and R. Lipp, "New Ballard Score, expanded to include extremely premature infants," The Journal of Pediatrics., vol. 119, pp. 417-423, 1991.

[33] J. M. Meijer, P. G. Pieper, W. Drenthen et al., "Pregnancy, fertility, and recurrence risk in corrected tetralogy of Fallot," Heart, vol. 91, pp. 801-805, 2005.

[34] H. Kaur, V. Suri, N. Aggarwal, S. Chopra, R. Vijayvergiya, and K. K. Talwar, "Pregnancy in patients with Tetralogy of Fallot: outcome and management," World Journal for Pediatric and Congenital Heart Surgery, vol. 1, pp. 170-174, 2010. 